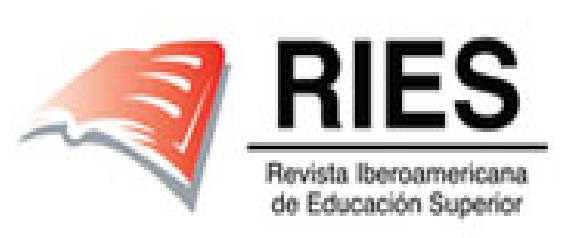

Revista Iberoamericana de Educación Superior

E-ISSN: 2007-2872

emmaro@unam.mx

Instituto de Investigaciones sobre la

Universidad y la Educación

México

Santillán-Briceño, Victoria-Elena; Ortiz-Marín, Ángel-Manuel; Arcos-Vega, José-Luis El poder y las prácticas de poder de la universidad pública: Universidad Autónoma de Baja California

Revista Iberoamericana de Educación Superior, vol. I, núm. 2, 2010, pp. 33-58

Instituto de Investigaciones sobre la Universidad y la Educación

.jpg, México

Disponible en: http://www.redalyc.org/articulo.oa?id=299123994003

Cómo citar el artículo

- Número completo

- Más información del artículo

Página de la revista en redalyc.org

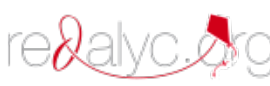

Sistema de Información Científica

Red de Revistas Científicas de América Latina, el Caribe, España y Portugal

Proyecto académico sin fines de lucro, desarrollado bajo la iniciativa de acceso abierto 


\title{
El poder y las prácticas de poder de la universidad pública: Universidad Autónoma de Baja California
}

\author{
Victoria-Elena Santillán-Briceño, Ángel-Manuel Ortiz-Marín y José-Luis Arcos-Vega
}

\begin{abstract}
Resumen
Esta investigación se realizó en la Facultad de Ciencias Humanas de la Universidad Autónoma de Baja California; los sujetos o unidades de análisis prioritariamente considerados fueron los académicos participantes en el proceso de diseño curricular, identificados mediante los criterios del muestreo teórico. El foco de interés se ubicó en la comprensión del tejido social del poder y su ejercicio en la definición de un curriculum por competencias en el área de las ciencias humanas. El acto educativo lo construyen y realizan individuos que ante todo son sujetos sociales y como tales entidades subjetivas que mediatizan la estimulación del entorno y elaboran su propia interpretación del mundo, dando significados particulares a la realidad. Las relaciones sociales de poder se configuraron en torno al dominio de las preocupaciones disciplinares y a la disputa epistemológica por definir el paradigma científico que provea la definición legítima de la realidad, en torno a tres preocupaciones: la lucha por el dominio y el control del espacio (facultad), el del saber (disciplina), y el de la autoridad formal (dirección).
\end{abstract}

Palabras clave: poder, diseño curricular, competencias, saber y académicos.

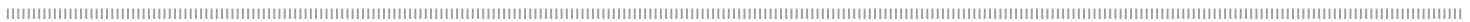

Victoria-Elena Santillán-Briceño

vicky@uabc.mx

Doctora en Ciencias de la Educación, Universidad Autónoma del Estado de Hidalgo. Investigadora de

la Facultad de Ciencias Humanas, Universidad Autónoma de Baja California. Temas de investigación:

diseño curricular; poder, educación y desarrollo humano.

\section{Ángel-Manuel Ortiz-Marín}

mortiz49@yahoo.com

Posdoctor en Ciencias Sociales con especialidad en Sociología Política, Universidad Nacional de

Córdoba, Argentina. Investigador de la Facultad de Ciencias Humanas, Universidad Autónoma de

Baja California. Temas de investigación: políticas públicas; poder y ciudadanía; culturas ciudadanas

juveniles; educación y desarrollo humano.

José-Luis Arcos-Vega

arcos@uabc.mx

Doctor en Ciencias de la Educación, Universidad Iberoamericana. Investigador del Instituto de Ingeniería, Universidad Autónoma de Baja California. Temas de investigación: educación superior, calidad y vinculación. 


\section{O poder e as práticas de poder da universidade pública: Universidade Autônoma} de Baja California

\section{Resumo}

Esta investigação foi realizada na Faculdade de Ciências Humanas da Universidade Autônoma de Baja California; os sujeitos ou unidades de análise prioritariamente consideradas foram os acadêmicos participantes no processo de desenho dos planos de estudo, identificados através dos critérios de amostragem teórica. O foco de interesse se localizou na compreensão do tecido social do poder e seu exercício na definição de um curriculum por competências na área das ciências humanas. O ato educativo é construído e realizado por indivíduos que, acima de tudo, são sujeitos sociais, e como entidades subjetivas que midiatizam a estimulação do entorno e elaboram a sua própria interpretação do mundo, dando significados particulares à realidade. As relações sociais de poder se configuraram ao redor do domínio das preocupações disciplinarias e à luta epistemológica por definir o paradigma científico que forneça uma definição legítima da realidade, em torno de três preocupações: a luta pelo domínio e o controle do espaço (faculdade), o do saber (disciplina), e o da autoridade formal (direção).

Palavras chave: poder, desenho de planos de estudo, competências, saber e acadêmicos.

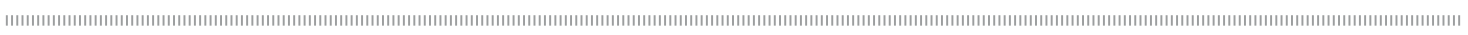

Power and power practices in public universities: the Autonomous University of Baja California

\section{Abstract}

This research was conducted in the Human Sciences School of the Autonomous University of Baja California; the main subjects or units of analysis considered were the academicians involved in the process of curricular design, who were identified using theoretical sampling criteria. The focus of interest was on understanding the social fabric of power and its exercise in defining a curriculum by skills in the human-sciences area. The act of educating is shaped and carried out by individuals who above all are social beings, and as such are subjective entities that manipulate environmental stimuli and draw up their interpretation of the world by giving specific meanings to reality. Social power relations were configured through mastery of disciplinary concerns and the epistemological dispute over defining the scientific paradigm that provides the legitimate definition of reality on the basis of three approaches: the struggle for mastery and control of space (skill), of knowledge (discipline) and of formal authority (management).

Key words: power, curricular design, competencies, knowledge and academicians.

Recepción: 17/12/2009. Aprobación: 28/01/2010. 


\section{Introducción}

La posmodernidad como condición histórica se corresponde con una dimensión de significación que reconfigura las condiciones y la organización de la vida social, cultural y política, representada en la construcción de una significación distinta de la realidad. Este escenario define un marco de contingencias y relaciones sociales asociadas con comportamientos y valores que se consideran deseables. De esta forma, cumple su primacía ejerciendo presión sobre las instituciones y actores sociales, al generar coyunturas que dan lugar a la modificación de las formas de producción, distribución y legitimación del conocimiento, en una corriente de pensamiento en pro de la revisión y evaluación permanente de la calidad en la educación. Aparece entonces el rendimiento de cuentas como el acto que avala el valor del saber y su certificación, y con ello la transformación de su organización y enseñanza.

Con estas premisas se asume que, en el campo de la educación, las instituciones educativas se muestran como el espacio social de legitimación de la producción y transmisión del conocimiento, en el aval de la demanda por cierto saber, saber hacer, habilidades, competencias y destrezas valoradas socialmente para el desempeño de determinada actividad productiva, bajo el desarrollo de acciones de planeación y de procesos de diseño curricular (DC), organizados en torno a la jerarquización del saber. Esta preferencia se asocia a la valoración de algunos saberes sobre otros, resultado por una parte de la existencia de condiciones estructurales que los regulan y, por otra, de las prácticas de confrontación entre distintos grupos y actores, así como de su relación con éstos y con la propia institución escolar, además de sus propias trayectorias e identidades disciplinares. Tal distribución del saber expresa, sin lugar a dudas, su poder simbólico.

Desde esta urdimbre de significados y representaciones se puede decir que el DC se ordena y construye en forma de espacio social, sobre la base de principios de diferenciación que dirigen las percepciones y las interacciones de los sujetos o agentes, como los denomina Bourdieu (1983), para recuperar la capacidad inventiva y activa de los agentes actuantes, con la cual construyen su propia visión, desplegando su acción y deseos en función de su habitus (Flaschland, 2003). Esta aproximación posibilita abordar en el estudio la dimensión socio-cultural e histórica de los procesos curriculares, cuya definición se encuentra anclada y sujeta no sólo a disposiciones de orden educativo, sino también a las de orden económico, político y, por supuesto, cultural, determinadas éstas por las condiciones del entorno inmediato. Asimismo, se pone en evidencia su identidad de práctica simbólica objetivada e instituida por su poder de construcción, fundado en las representaciones, interpretaciones e interacciones de los agentes en un espacio social diferenciado.

Precisamente en este contexto, caracterizado por el aseguramiento de la pertinencia, y en una cruzada por la eficiencia y eficacia de los procesos educativos, la Facultad de Ciencias Humanas (FCH), de la Universidad Autónoma de Baja California (UABC), emprendió en 1988 un proceso de evaluación de éstos. Este proceso duró cinco meses y culminó con la decisión de efectuar la reestructuración de los planes de estudio, a partir de la realización de un esfuerzo de diseño curricular. El tema del presente trabajo es el poder en el DC, específicamente, la expresión de las relaciones de poder en el también denominado proceso de prescripción curricular. Tal proceso se efectuó durante un periodo de cuatros años, de agosto de 1998 a octubre de 2002, y durante éste el grupo de trabajo, conformado por académicos de las disciplinas del área de la educación y las ciencias sociales (ciencias de la educación, psicología, ciencias de la comunicación y sociología), transitó por distintos momentos de trabajo colectivo y colegiado 
que concluyó con la aprobación e implementación de la propuesta de un curriculum flexible por competencias en agosto de 2003.

En este marco, se asume como problema la siguiente pregunta de investigación: ¿Cómo se expresan las relaciones de poder en el proceso de diseño curricular de la Facultad de Ciencias Humanas de la Universidad Autónoma de Baja California de 1998 al 2003?

A partir de ella, los objetivos propuestos son:

\section{Objetivo general}

Explicar el ejercicio de las relaciones de poder en el proceso de diseño curricular de la $\mathrm{FCH}$ de la $\mathrm{UABC}$, a partir de la recuperación y reconstrucción de la experiencia de los actores.

\section{Objetivos específicos}

- Modelar las relaciones de poder manifiestas en la construcción del diseño curricular en la $\mathrm{FCH}$.

- Aportar elementos analíticos para la comprensión de las relaciones de poder y su ejercicio como prácticas socio-académicas en el campo educativo.

La premisa principal establecida para la investigación establece que: Las relaciones de poder en el proceso de diseño curricular son efecto de ejercicios desiguales de poder entre los académicos.

Otras premisas consideradas señalan que:

- En el diseño curricular, las relaciones de poder son manifestaciones de la percepción de los distintos enclaves disciplinares que generan prácticas diferenciadas de ejercicio del poder.

- El diseño curricular, como acto social institucionalizado del campo educativo, es una práctica académica de recreación simbólica y reconfiguración de las relaciones de poder de los académicos.
La investigación propone e identifica, en relación con la pregunta de investigación y de los objetivos señalados de indagación y comprensión profunda, el desarrollo de las siguientes categorías analíticas:

\section{Relaciones de poder}

Prácticas interactivas de lucha simbólica y real articuladas entre los agentes en disputa por la jerarquía al interior del campo y la autoridad de la representación válida del mundo (Bourdieu, 1993), de la legitimación del saber y la verdad, a través de la puesta en juego de una amplia variedad de recursos, posiciones y posesiones, modalidades de participación, estilos de comunicación, representaciones, significados, estrategias e intereses expresados en el tejido social con la intención de lograr ciertos objetivos o privilegios; en su defecto, protegerse o evitar ciertas consecuencias o efectos. Interrelaciones manifiestas en un complejo sistema de relaciones de fuerza de origen desigual, caracterizadas por la circulación del poder en una dinámica eminentemente relacional, estructurada a partir de la existencia de un sujeto de poder, lo mismo que de un campo de respuestas, invenciones y efectos ante éste (Foucault, 1991), en un proceso constante de comunicación o interacción.

\section{Habitus}

Matriz de percepción, representación y práctica de los agentes, que incluye lo aprendido, las reglas del juego incorporadas, la forma de ver, ser y actuar, moldeada por las estructuras sociales; una visión del mundo y la realidad que designa un estado habitual de actuación ajustable a la amplitud de las situaciones. Se trata del sistema social y subjetivo de disposiciones cognitivas y emocionales, relativamente permanentes, traducidas en esquemas de pensamiento y conducta en cuanto orden de acción, principio generador en un determinado entorno social, de representaciones que condicionan cierta actuación (Bourdieu, 1990). 


\section{Estrategias de ejercicio del poder}

Entendidas como los recursos e instrumentos de acción y pensamiento utilizados por los agentes para imponer, influir o conducir conductas, alcanzar intereses, objetivos y cubrir necesidades (Ball, 1989), que en la práctica regulan y redistribuyen las relaciones de fuerzas del tejido social. Medios definidos de acción, sustentados en el uso de códigos, percepciones y representaciones de los individuos o grupos para el ejercicio del poder, a través de la recreación de la forma peculiar de realizar en lo cotidiano el trabajo académico, en términos de prácticas socio-académicas que despliegan la visión de los actores.

\section{Intereses de poder}

Se reconocen como las intenciones o necesidades procuradas por los actores (Ball, 1989), producto de la representación e interpretación del contexto histórico-social y de la biografía singular en la producción de las prácticas y actuaciones de los agentes en el espacio de la cotidianidad socioeducativa. Son los medios de acción en situaciones particulares, que transfiguran simbólicamente los móviles, y posibilitan la existencia y la reproducción de relaciones de poder, así como su ejercicio dentro de una trama de significados en procesos permanentes de interacción social (Bourdieu, 2000).

\section{Identidad disciplinar}

Entidad social y de significación construida por los agentes a partir de la subjetividad socializada en la unión de dos nociones: el campo de conocimiento y el grupo asociado a él, caracterizando un modelo de interacción, comportamiento y comunicación (Becher, 2001). Cristalizada en los referentes identitarios del sentido de pertenencia y afiliación colectiva, de los significados, el lenguaje, los hábitos, los gestos, las prácticas, las relaciones, las estrategias, los intereses, el saber profesional y específico, la trayectoria desarrollada con base en el trabajo cotidiano, en consideración de la cultura institucional; en otras palabras, un estilo de vida académica. Referentes simbólicos e imaginarios tangibles a manera de reflejo de conocimientos útiles y prácticos para manejar, entender y ordenar el mundo inmediato, expresados en forma de reglas altamente ritualizadas y racionalizadas, con las cuales los agentes educativos inciden, configuran y alteran, histórica y socialmente, el campo educativo y la producción del conocimiento (Bourdieu, 2003).

En consecuencia, el estudio tiene el propósito de introducir a la comprensión de la realidad educativa al ponderar la visión local del poder, la de su microfísica, de acuerdo con Foucault (2005), o de micropolítica, tal como lo argumenta Blase (1991), al colocar el acento en el estudio de su producción, circulación, ejercicio y en el de sus efectos sobre el trabajo educativo, lo que hace inminente la expresión e identificación de un conjunto de sus propiedades en torno a un escenario y espacio particular, limitado en este caso al referente del DC llevado a cabo en la FCH de la UABC entre 1998-2003.

Reconstruir la experiencia del poder en la organización del conocimiento o del saber para dar cuenta de su funcionamiento y manifestación, a través del avistamiento de cómo se toman las decisiones, se vuelve factible en el análisis de las comunicaciones, discursos y actuaciones cotidianas de los actores. En este sentido, definición curricular estructurada relacional y simbólicamente, donde el poder representa transfigurativamente el capital a poseer, y la legitimación del saber o el conocimiento, uno de los intereses en juego, en lucha o en disputa.

\section{Consideraciones teóricas}

\section{Poder}

Al hablar sobre educación es frecuente y común encontrar expresiones que al parecer refuerzan el 
nexo tácito entre poder y saber, pero dilucidar cómo se gesta o dimensiona dicha vinculación, requiere la ponderación de posicionamientos teóricos que aporten referentes conceptuales para el entendimiento del carácter de tal establecimiento. Precaución que inscribe dos suposiciones en la indagación. Una inserta en la identificación de los actores como agentes que producen o reproducen las estructuras sociales; la otra, la determinación de la génesis de una situación particular, ya que las prácticas sociales siempre adoptan una forma diferente.

En esta aproximación es posible identificar dos amplios esquemas de representación. Uno de ellos, informado en la línea interpretativa que ve al poder como una instancia negativa, de represión, control e inhibición, que actúa desde una perspectiva superior sobre el cuerpo social, que lo convierte en su propio objeto e instrumento; el otro, anclado en el andamiaje de elementos fundantes y condicionantes de lo social, expuestos en la existencia de determinadas estructuras, relaciones y prácticas que enmarcan la vida de los hombres.

En esta ambivalencia se expresa la asunción relacional de la sociedad. En esencia, el poder se define como una relación recíproca que enlaza a dominantes y dominados en la racionalidad política de la imposición o dominio articulado en la obediencia. Se trata de un poder racional y normativo entre los subordinados y el titular, a causa de un vínculo formal que lo describe como un esquema justificado de autoridad (Weber, 2007). Tal modalidad especial de poder detona la posibilidad genérica de imponer la propia voluntad dentro de una relación social, instaurada en el basamento de la legitimidad.

Bourdieu (1983) y Foucault (1991) concuerdan con la visión de la construcción social del poder, al destacar sus efectos sobre los procesos de conformación de la subjetividad de las personas, desentrañando la especificidad de las relaciones sociales. Sin embargo, Bourdieu (2000), en una postura más universal y generalizadora, centra el énfasis de sus postulados en la producción relacional de la realidad; esto es, en la estructuración de las estructuras sociales. Por el contrario, Foucault (1991) rescata en su punto de vista la idea de la impropiedad de la universalidad del poder, pues ante todo ha de ser entendido rigurosamente en términos de relaciones de fuerza, por tanto coextensivo a los contextos singulares en los que se produce. Dicho de otra manera, se centra en su producción, en cómo se construye y reproduce en lo particular, a lo largo del tejido social.

\section{Bourdieu: el poder simbólico}

Dentro del esquema estructuralista de Bourdieu (1990), son las posiciones y posesiones de los agentes las que en conjunto determinan la percepción del mundo o la pluralidad de visiones de la realidad, que proveen la base para luchas simbólicas por el poder de producir e imponer la visión legítima del mundo, las cuales pueden tomar dos formas diferentes: la objetiva, destinada a hacer valer ciertas realidades de representación individual o colectiva; y la subjetiva, que implica el cambio de las estructuras cognitivas, que son las categorías de percepción y apreciación del mundo social (Bourdieu, 1993).

Diferencias que en la realidad misma de la vida funcionan positiva o negativamente como signos de distinción (Bourdieu, 1993). Así, las relaciones objetivas tienden a reproducirse en interrelaciones de poder simbólico, entendido no como un tipo específico de poder, sino como un aspecto presente en la mayoría de las estructuras relacionales para ser desplegado rutinariamente en las prácticas sociales sin uso de la fuerza física. En estas relaciones los agentes empeñan la eficacia de sus inversiones, para volverlas simbólicamente eficientes en el logro de derechos y ventajas de reconocimiento.

En este sentido, el poder simbólico consagra y revela cosas que ya existen, haciendo visibles y explícitas las divisiones sociales. Es el poder político 
por excelencia: para hacer grupos, así como para manipular la estructura objetiva de la sociedad. Es legitimador, suscita el consenso tanto de los dominadores como de los dominados, construye el mundo en cuanto supone la capacidad de imponer la visión legítima de las divisiones sociales de éste; se apoya en la violencia simbólica y en el carisma que se ejerce sin coacción física, a través de diferentes formas que configuran las mentes y le dan sentido a la acción. Dentro de este marco estructural-reproduccionista, se reconoce como producción social y simbólica, en lo concreto, el poder de hacer ver y hacer creer (Bourdieu, 1993).

\section{Foucault: la producción del poder}

La perspectiva de la microfísica del poder, reconoce que éste se manifiesta en una red de relaciones asimétricas de fuerza, por tanto, es elemento constitutivo de su conformación. Éste es inminente y propio del dominio en el que se ejerce, pues designa una compleja relación estratégica desencadenada en la complejidad del tejido social. En este sentido, y a partir de su estatus ontológico, el poder está por doquier, no como privilegio acumulado, sino más bien se produce a cada instante, en todos los puntos. Está en toda relación, no es que lo englobe todo, sino que está y viene de todas partes (Guareschi, 2005).

Este concepto presta atención a las dimensiones productivas del mismo, a las formas en que actúa a través de las acciones individuales, a manera de disposiciones, maniobras, tácticas, técnicas o funcionamientos que adjudican a los sujetos la capacidad de actuar, pensar y sentir (Flyvbjerg, 2001), lo que lo describe como técnica de dominio y control que tiene por efecto conducir conductas al ser real, objetivo, activo y dinámico, más que un privilegio que se detenta. Así, el poder sólo existe en el acto concreto de su ejercicio, en la especificidad de diversas contingencias, pues "el poder no se posee, se ejerce" (Guareschi, 2005: 381), dentro de la singularidad de las relaciones de fuerza, que es donde se ubica su origen y duración.

Por consiguiente, las vicisitudes de su producción se ubican en el espesor de la sociedad, en la trama relacional cuya continuidad se articula en una serie de mecanismos complejos que en su ejecución las hace efectivas relaciones de poder, y dado que está en toda relación social, de un punto a otro, su transfiguración es la de ser vehículo y expresión del mismo (Acanda, 2003). La cuestión es que el poder no es una propiedad adquirida, no se conserva de una vez y para siempre, sino que es el efecto de un conjunto de posiciones estratégicas que a veces acompaña a los dominados. No aplica obligación, ni prohibición a quienes no lo tienen, más bien los invade, se apoya y pasa por, y a través de ellos, de la misma forma que aquéllos, en su lucha contra él (Foucault, 2005).

En este sentido, las visiones ofrecidas por Bourdieu (2000) y Foucault (2005), junto a la de Weber (2007), proyectan dentro de un enfoque relacional el origen inminente del poder, que lo aleja del sentido de propiedad, y lo traslada al terreno de la acción y la práctica social.

\section{Curriculum: práctica cultural}

Hablar sobre curriculum no es un ámbito menos complicado que el del poder, pues las ideas sobre éste tampoco son universales, por el contrario, en la medida que es producto de su época, ubicado históricamente, las formas en que se practica y vive no han sido las mismas. En términos de las perspectivas que aparecen en los curricula, se reflejan representaciones diferentes acerca de la educación y de la sociedad, de las necesidades y de los problemas sociales, los de orden teórico y práctico.

Curricularmente hablando no hay leyes universales, sino intereses humanos fundamentales que influyen en la forma de constituir o construir el conocimiento. La cuestión es entonces qué o cuáles creencias llevan a un tipo determinado de práctica 
educativa, en la noción de que el conocimiento es algo construido por las personas en su conjunto.

En este escenario, la construcción del currriculum ocupa una posición estratégica, precisamente por ser el espacio en el que se concentran y desdoblan las luchas en torno a los diferentes significados sobre lo social y lo político, en virtud de que este último no existe aparte de ciertas creencias y valores. A partir de esta visión general, el principio más importante a reconocer es que el curriculum es una construcción social, cuya forma y objetivos están determinados por intereses humanos fundamentales, lo que presupone que cada contexto educativo es al mismo tiempo social (Kemmis, 2003), por lo que en el curriculum quedan registrados los restos de las disputas por el predominio cultural.

De esta forma, el DC se identifica en términos de un proceso caracterizado por la toma de decisiones. De acuerdo con Guarro, quien es retomado por Hernández (1998: 26), es "el proceso de toma de decisiones para la elaboración del curriculum, que configura flexiblemente el espacio instructivo [...] en una visión anticipada". Es decir, éste es más una permanente solución de problemas que una aplicación lineal de ciertos principios y reglas, es un proceso permanente de negociación. Como consecuencia, la educación y el curriculum son campos culturales, pues en lo fundamental, su existencia y funcionamiento se constituye en las prácticas de la significación y surgen a partir de un conjunto de circunstancias históricas (Tadeu da Silva, 1998).

Tal parece, como lo señala Tadeu da Silva (1998), que en el curriculum ocurre un juego decisivo, en él se entrecruzan prácticas de significado y sentido, contestado, disputado y conflictivo. La lucha es por la hegemonía, por el predominio cultural, donde el significado es al mismo tiempo objeto, objetivo e instrumento. Rasgos que demarcan su condición de práctica cultural; es decir, de significación, en la que los grupos sociales, especialmente los dominantes, expresan su visión del mundo, su verdad. En ese nivel, el curriculum se concentra y desdobla como elemento simbólico del proyecto social de los grupos en el poder.

De esta forma, la prescripción curricular es el producto de fuerzas contendientes entre grupos emergentes y grupos conservadores, en un proceso de hegemonía-contrahegemonía, siendo necesario el consenso y la legitimidad de acuerdos sociales como expresión del poder, sin que esto signifique que el conflicto desaparece, por el contrario, éste permanece alimentando las relaciones de fuerza (Apple, 1990). Así, el curriculum nunca es un mero agregado neutral de conocimientos, forma parte siempre de una tradición selectiva, de la selección de alguien, de alguna visión de grupo con respecto al saber que se considera legítimo, de la decisión de definirlo como más justificado, como el oficial; descalificando cualquier otro tipo de conocimiento, efecto de las tensiones y compromisos culturales, políticos y económicos que hablan acerca de quién o quiénes sustentan el poder.

Por otra parte, Giroux (2003) puntualiza que si bien los procesos de construcción curricular son espacios de conflicto y lucha permanente por el poder, deben simultáneamente reconocerse como espacios de construcción cultural, idea circunscrita en el concepto de política cultural. En su consideración, el curriculum implica la construcción de significados y valores culturales, pero igualmente es el espacio donde éstos se crean y producen socialmente.

Visión crítica ampliada en las ideas de Goodson, al referir que el curriculum es una "construcción social que refleja la condición de los individuos implicados y las jerarquías sociales que existen en la sociedad en general" (Goodson, 2000: 10). Esto significa que los procesos y decisiones que le dan forma son actos políticos marcados por juegos de poder, entendido como una "fuerza dialéctica que impacta a las personas y funciona a través de ellas" (Goodson, 2000: 24). El poder constituye 
una fuerza básica de la existencia humana desplegada tanto por los individuos como por los grupos. Visión construccionista en la que se propone que debe observarse el contenido del curriculum a fin de revelar los intereses políticos ocultos, siempre en correspondencia con los modos idiosincrásicos específicos de un contexto.

\section{Poder y saber}

De acuerdo con la literatura, parece que la presencia y el concurso del poder en las actividades del campo de la producción del saber, el educativo, se asume bajo tintes de facto, donde ya no es novedad ni se cuestiona; más bien su intervención se evidencia y se discute de manera relevante. Este espacio social se caracteriza por luchas y confrontaciones entre grupos que aparentemente se encuentran en una doble búsqueda: de la detención del saber legítimo y del logro de posiciones de beneficio. Así, las relaciones de poder se construyen como objeto de conocimiento y las prácticas académicas específicas, reconocidas y validadas al interior del campo, en su vehículo de expresión.

Una posición fundamental para el avistamiento de la conexión entre el poder y el DC es aquella en la que se aborda su uso, la forma en que al interior de las instituciones educativas se concretiza y se utiliza. En esta especificidad intraorganizativa se encuentra el enfoque de la micropolítica de la enseñanza, también denominada política organizativa, interesada en la valoración de las relaciones de poder dentro del campo educativo, destacando principalmente los estudios desarrollados por Stephen J. Ball (1989) y Joseph Blase (1991). Se centra en la consideración de la vida social de la escuela, en su ordenación a partir de la búsqueda de acuerdos y la resolución de conflictos. En este espacio se conjugan dos supuestos, el primero de ellos, que las escuelas albergan diversas y muchas veces contradictorias estrategias de control, y el segundo, que son organizaciones jerárquicas controladas por sus miembros.
Derivada de tal consideración, la atención se coloca en el descubrimiento de lo que Ball refiere como el lado obscuro de la escuela: "luchas por el poder en forma de autoridad o influencia, la formación de grupos y coaliciones para conseguirlo, o bien, defenderse de él" (1989: 10); se organizan en torno a dos núcleos de poder: los profesores y la administración. De la lucha de intereses pedagógicos, profesionales y personales contra los intereses políticos. Se trata del poder del saber frente al poder político.

Tales dimensiones especifican el ámbito de la micropolítica de la escuela, definida por Hoyle, citado en Ball (1989), como esas estrategias con las cuales los individuos y grupos en contextos educativos, tratan de usar sus recursos de poder e influir para promover sus intereses particulares. Con mayor especificidad, considera las actividades llevadas a cabo dentro de la organización para su desarrollo y ejercicio con el propósito de obtener los resultados deseados en situaciones de disentimiento, ya que las prioridades están dadas en mayor proporción por las necesidades prácticas, por la supervivencia. En esencia, la vida organizativa de la escuela se encuentra en el orden de la negociación, construida en el arreglo y los acuerdos como reglas para que tenga lugar la concertación, descrita como "el producto de los conflictos entre los individuos por mediación de las diferencias de poder existentes en la estructura" (Ball, 1989: 36).

La micropolítica de la educación sintetiza el uso del poder por parte de los profesores en la cotidianidad del conflicto, la cooperación, la influencia, la protección y las relaciones, en función de lo que se piensa, de las convicciones y de los enclaves sociales. Blase (1991) enfatiza que esta perspectiva se ocupa de lo que hacen los individuos y los grupos dentro de una organización para alcanzar sus propósitos y satisfacer sus intenciones.

Precisamente en este espacio de la enseñanza es posible identificar cómo los profesores usan el 
poder formal e informal para conseguir sus fines en las organizaciones escolares. De igual forma, es el espacio de la competencia, de la cooperación, y se observa en él cómo se apoyan mutuamente las personas en tales disputas, al atender las ideas y los pensamientos aplicados por aquéllas; eso que no se habla, ni se observa con facilidad (Blase, 1991). Junto con Blase, otros autores citados por él, como Bacharach y Lawler, postulan que la política de las organizaciones tiene que ver con el uso estratégico del poder para conservar o conseguir el control de los recursos materiales o simbólicos.

De manera sucinta, resalta la idea de la no neutralidad del curriculum, de proceso mediado, producto de intercambios intensos de contenidos culturales, derivado de procesos de toma de decisiones simbólicamente centradas en el control para el ejercicio del poder, que pasa por el filtro de los procesos de interpretación mediante actos de representación que tienen como principal propiedad el contenido de la subjetividad por parte del sujeto. En él se encuentran considerados los códigos de valores socialmente asumidos o elaborados por miembros de una colectividad en un momento socio-histórico particular, culturalmente determinado.

En este tenor, Becher (2001) destaca la estrecha correlación existente entre las prácticas habituales de una disciplina con las características de los dominios de investigación, lo que significa identificar las interconexiones entre las culturas académicas y la naturaleza del conocimiento. En este sentido, las colectividades son fenómenos configurados socialmente a través de disposiciones predecibles, adoptadas por un conjunto de personas que actúan dentro de cierto círculo disciplinar.

Estos supuestos revelan que las características cognitivas y sociales no son fácilmente separables, y que cuando se habla de disciplina en ella se unen dos nociones: la del particular campo de conocimiento y la del grupo de académicos asociados a él, pues las disciplinas se definen igual por los contenidos intelectuales, que por las personas que las adoptan, en otras palabras, por las comunidades a las que les pertenecen. Lo que significa que cualquier persona que ingrese a un nuevo grupo con la intención de ser un miembro competente, debe aprender a cumplir sus normas culturales fundamentales.

Con ello se destaca que todos los académicos, al pertenecer a una comunidad de conocimiento, comparten intereses que los apartan de los demás (Becher, 2001), en una lógica de rivalidad entre grupos en competencia, evidente en momentos de amenaza. Esto permite hablar, en función del contexto, de identidad de grupo y, desde otro punto de vista, de cultura hacia la interacción entre grupos, a menudo mutuamente hostiles. Igualmente, las redes y comunidades disciplinares pueden caracterizarse por su modelo de interacción, con diversos grados de convergencia, al manifestar un fuerte sentido de colectividad y mutua identidad; o divergentes, es decir, cismáticas e ideológicamente fragmentadas.

En referencia, un sistema de educación siempre está investido de múltiples funciones socialmente determinadas y asignadas por los grupos que la componen e incorporan su representación cultural. Así, "los diversos fines a los que puede servir un sistema educativo están desigualmente alejados de los fines que los diferentes grupos asignan, explícitamente o no, a la educación y, por eso, desigualmente conformes a sus intereses" (Bourdieu y Passeron, 2003: 98), situación que concentra y concretiza su configuración de espacio de lucha, mediante la reproducción cultural y social.

Ello significa que los problemas de poder en el campo de la educación, específicamente en las instituciones educativas, como es el caso de las universidades, guardan relación proporcional con la construcción de la autoridad organizacional, que tiene que ver con las fórmulas estructurales creadoras de las relaciones de poder, así como de 
su consolidación, cambio o reforma para fortalecer o debilitar el o los núcleos de poder académico, tal como lo describe Acosta (2002). Cuestión que evidencia que, si el poder es esta relación de dominación legítima entre los que mandan y los que obedecen (Weber, 2007), el acto de autoridad derivado de esta ordenanza implica la formación de coaliciones cambiantes y grupos de interés que producen procesos de decisión bajo reglas y normas emergentes del libre juego del mercado político-académico interno, donde el conflicto es tanto esperado como legítimo (Acosta, 2002).

Atender los procesos de autoridad política supone la existencia de un orden político que se encuentra unido a las tensiones de diversas lógicas de acción de las redes de poder organizadas, sujetas a contingencias inestables y ambiguas que configuran espacios donde las redes de poder se superponen para negociar cotidianamente sus intereses. Óptica analítica de interés promisorio en la complejidad de la dinámica en la que acontecen los intercambios y juegos políticos que acaecen entre los grupos e individuos que conforman la comunidad política-académica (Acosta, 2002). Asunto crucial en el que el escrutinio de las relaciones y equilibrios de poder se vuelve sensible a las tramas de estructuración del orden político, que lía siempre una cuestión de poder, cuyo eje central se dispone en la mezcla de demandas académicas, además de políticas, que confluyen arreglando arenas de negociación y enfrentamiento por recursos simbólicos, poder y prestigio.

Así, la existencia de autoridad abona una "estructura de gobierno donde autoridades y grupos subordinados establecen una relación de dependencia" (Acosta, 2006: 26). En esta dinámica, la gobernabilidad (governability) como dimensión política del gobierno simboliza las agendas, los acuerdos y el esquema básico de los intercambios políticos entre los actores, pues tiene que ver con los estilos de conducción, así como con los modelos de toma de decisiones, es decir, con la particular forma en que se construye el poder al interior de las instituciones. En sentido estricto, alude a "la capacidad de las instituciones y del sistema de educación superior para atender demandas internas y externas" (Acosta, 2006: 36). Ello deja en claro, como establece el autor, que la conquista o el acceso al poder de ninguna manera asegura o garantiza el ejercicio eficaz del mismo, más bien se construye y adquiere bajo un conjunto de restricciones y oportunidades dadas, no siempre elegidas.

Realidad institucional en la cual el DC representa una lógica coyuntural no sólo para el mejoramiento de la calidad académica y en algunos casos de la eficiencia administrativa, sino además de estrecha vinculación con reformas de distribución individual o colectiva del poder.

\section{Metodología}

La metodología considerada para analizar y explicar cómo se expresan las relaciones sociales de poder en el referente empírico del DC es la de una investigación cualitativa que permite, por una parte, una descripción detallada del contexto en el que se dio la actividad y, por otra, su comprensión como suceso relacional interconectado por intereses y estrategias, arraigado en un proceso de mediación y expresión simbólica y material, organizado desde la subjetividad de los actores para ser recreado en la interacción social.

Investigación cualitativa en la que el abordaje del DC se acota a la dinámica del proceso, al de su condición de acto construido socialmente. Metodología pertinente en la focalización del objeto de estudio al descansar en la premisa de buscar entender los hechos desde la propia perspectiva del actor y con ello dilucidar las creencias y motivos que se hallan detrás de las propias acciones, de recrear lo que los individuos y grupos sociales piensan, creen y sienten (Kornblit, 2004), para en consecuencia comprender a profundidad cómo se 
ven las cosas. De ahí que, para el análisis cualitativo de la información, además de su ponderación en la recolección de la misma, conjuntamente con el examen de corte hermenéutico interpretativo, se asumen los postulados metodológicos de la Teoría Fundamentada (TF), con respecto a la exploración inductiva y al análisis cualitativo de todas las unidades informativas.

Específicamente, la perspectiva metodológica de la TF como postura investigativa de orden inductivo, permite la elaboración de una explicación comprensiva del fenómeno mediante la generación o descubrimiento de la teoría a partir de los datos obtenidos en la propia investigación, por medio de la codificación y categorización teórica y analítica de los mismos. Término utilizado por Strauss y Corbin para referirse a "una teoría derivada de datos recopilados y analizados por medio de un proceso de investigación" (2002: 13), en el distintivo de encontrarse fundada en aquéllos.
En esta investigación, los sujetos prioritariamente considerados fueron los académicos participantes en el proceso de DC, identificados mediante el muestreo teórico por criterio, donde los informantes satisfacen el criterio previamente determinado. Es decir, se revisan y estudian los casos que cumplen o satisfacen los criterios de importancia predeterminados, en el reconocimiento del valor potencial de cada caso para la comprensión teórica de la vida o el fenómeno social (Taylor, 1987) o, en otras palabras, para la investigación.

A partir de ello, se contempla la diversificación de la muestra con el fin de complementar las perspectivas de los informantes procurando la saturación teórica, a la que se llega una vez que los datos han dejado de ofrecer diferencias o distinciones conceptuales importantes, pues se dice que las categorías o conceptos se han saturado (Álvarez-Gayou, 2005).

Precisamente de tal observación, la población de estudio se identifica en dos categorías:

\section{Cuadro 1}

\begin{tabular}{|l|c|}
\hline Perfil grupo base & Perfil grupo base \\
\hline $\begin{array}{l}\text { 1. Académico integrante } \\
\text { del comité de reestructuración. }\end{array}$ & $\begin{array}{l}\text { 1. Participante en distintas fases } \\
\text { del proceso de diseño curricular. }\end{array}$ \\
$\begin{array}{l}\text { 2. Coordinador o representante } \\
\text { por carrera. }\end{array}$ & $\begin{array}{l}\text { 2. Académico de tiempo completo } \\
\text { o asignatura. }\end{array}$ \\
$\begin{array}{l}\text { 3. Representante de alguna } \\
\text { de las disciplinas: ciencias de la }\end{array}$ & $\begin{array}{l}\text { 3. Integrante de consejo académico, } \\
\text { técnico o universitario. }\end{array}$ \\
$\begin{array}{l}\text { y sociolón, psicología, comunicación } \\
\text { 4. Representante de alguna de las } \\
\text { disciplinas: ciencias de la educación, }\end{array}$ \\
\end{tabular}


1) académicos responsables del DC, quienes para efectos prácticos de referencia, se denominan grupo base, y 2) académicos partícipes del DC, a quienes se les denomina grupo de referencia.

La obtención de la información a través del método considerado, se desarrolló en dos amplios momentos: el primero de ellos, de carácter exploratorio, con el cual se inició la entrada al campo para el reconocimiento del escenario y los informantes, asimismo válido para iniciar la recolección sistemática de datos y la toma de decisiones metodológicas subsecuentes, a partir del desarrollo de una encuesta; y un segundo momento, centrado en la realización de entrevistas a profundidad para la obtención de datos descriptivos que permitieran la comprensión profunda de la perspectiva y experiencia particular de los informantes. Específicamente el primero de ellos, dirigido a académicos participantes del proceso de DC en algunas de sus fases, y el segundo, ordenado para la atención de los académicos responsables del DC.

Esta aproximación inició con el diseño de ambos instrumentos: encuesta y guía de entrevista, además de la identificación de los posibles informantes mediante la estrategia del muestreo teórico por criterio. En consideración de tales elementos, la encuesta fue aplicada a cuatro académicos de la Facultad, uno por cada una de las disciplinas. El cuestionario se integró con tres tópicos: noción de poder, principales rasgos y algunas expresiones $o$ manifestaciones del mismo en el trabajo académico, cuya aplicación consideró: el acuerdo previo con el informante, su administración de forma individual y personalizada, y su realización en el espacio de trabajo de cada uno de los encuestados.

En cuanto a la técnica aplicada para la obtención de los datos descriptivos, destaca la realización de entrevistas a profundidad a un total de nueve académicos responsables de la prescripción curricular, con el fin de posibilitar la exploración de lo sucedido con los sujetos en torno a esta situación concreta, y de cómo fueron afectados o impactados por ella (Quinn, 1980). Método con el cual se buscó, a través del encuentro o encuentros cara a cara, la comprensión de la perspectiva de cada uno de los informantes, tal y como la expresan en sus propias palabras, para identificar los significados asignados a tal situación, a partir del relato o discurso proporcionado, en un esfuerzo de recuperación de acceso indirecto al fenómeno.

Respecto del procedimiento para el análisis de la información, éste propiamente inicia con la recolección del mismo, apoyado en el método de comparación constante con base en palabras, conceptos e ideas para desarrollar categorías de información (Cresswell, 1998). Sustancialmente se retoman los postulados del análisis interpretativo propios de la $\mathrm{TF}$, potenciados en la comparación y la elaboración de preguntas, a partir de la codificación que permite fragmentar, conceptualizar e integrar los datos para identificar conceptos centrales, en torno a los cuales se desarrollan descripciones conceptuales con el propósito de crear una explicación o comprensión basada en su interpretación (Strauss y Corbin, 2002).

Para ello, todas las entrevistas realizadas fueron transcritas y revisadas, y posteriormente fueron depuradas e incorporadas al software Atlas.ti (versión 5.0), para su revisión analítica. Programa inspirado en la TF que aporta los recursos adecuados para el análisis científico de la información alcanzada en la investigación a través de su codificación y comparación constante, en el principio de desarrollar la interpretación de todo lo observado y registrado para generar una explicación teórica. Una de sus fortalezas consiste en la capacidad de mostrar interconexiones entre los datos y la posibilidad de relacionarlos para elaborar diagramas conceptuales de relaciones verticales y horizontales entre los mismos. Proceso que refleja patrones de integración entre los datos y categorías que permiten ver la teoría emergente. 
En su conjunto, el análisis de los discursos, así como la información categorizada, permitió revelar las conexiones entre categorías. Además, fue posible elaborar y representar gráficamente las redes semánticas (networks) que muestran dichas relaciones conceptuales mediante el uso de las citas (quotations) y los códigos (codes), en las que quedan identificadas y expresadas las representaciones e ideas de los actores, y su conexión con las categorías analíticas. En esencia, su integración en un esquema teórico que propone una explicación convincente del comportamiento con el propósito fundamental de generar la comprensión del fenómeno particular (Strauss y Corbin, 2002).

\section{Resultados}

El proceso interpretativo de la información se desarrolló a partir de triangular los marcos teóricos y los datos empíricos con las categorías analíticas centrales de la investigación, correlacionando los conceptos abstractos con el objeto de estudio.

De esta manera, se identifica que el ejercicio del poder en el espacio de la producción del saber, presupone el reconocimiento del trabajo educativo como un proceso simbólico de significación y producción de sentido, situación que identifica al curriculum no sólo en el centro de las relaciones sociales y culturales, sino de los nexos entre saber $y$ poder. Lo anterior denota el vínculo indisociable entre significados y acción, y la existencia de prácticas sociales institucionalizadas que configuran estilos habituales y ritualizados de actuación que simbolizan, en un cuadro interactivo, formas de dominación para la legitimación del saber, materializadas en estructuras de relación articuladas entre los agentes que lo construyen y le dan sentido, dentro de un contexto histórico-social específico, a partir de la pluralidad de fuerzas inminentes y propias del dominio en el que se ejercen, develando al tejido social como una trama singular de relaciones de poder.
Para abordar este tema, los rasgos densidad comunicativa y solución de problemas, son elementos clave para explicar varios fenómenos casuales presentes en la comunicación y el discurso de los procesos sociales. En el primero de los rasgos, se puede observar que junto con las características estructurales de los grupos académicos, se encuentran los elementos simbólicos de significación y comunicación compartidos, que ejercen su dote de fuerza integradora. Aquí, se encontraron superposiciones en las opiniones de los miembros del grupo. Si bien en su mayoría los entrevistados enuncian que la comunicación puede describirse como directa y fluida, ésta también se encontraba cargada de fuertes desencuentros y discusiones álgidas y duras, como dijo uno de los entrevistados, "había momentos tensos" (Entrevistado 2, p. 2). Estos aspectos comunicativos son concomitantes a la maquinaria de socialización, e incidentalmente impactan en el terreno de las disputas y las controversias; están comprometidos con la naturaleza de las dificultades o conflictos en el trabajo curricular y, por su origen, se describen como personales o afectivos; teóricos y epistemológicos; de compromiso y político-administrativos.

Tensiones que en conjunto inquieren, como señala Acosta (2006: 22), "esencialmente un cambio en las reglas de producción y distribución del poder" político-académico-institucional, para el trámite de una modificación en la capacidad de gobernación, alterando la gobernabilidad en el marco de las relaciones de poder coligadas con el conflicto de intereses, ideologías o proyectos de muy diversos órdenes y alcances.

De manera paralela, otra propiedad de la comunicación se reconoce en el uso del lenguaje; de acuerdo con los académicos entrevistados se observaron dos cualidades, la de su especialización y la de su expresión no verbal, como formas efectivas de comunicar mensajes. En este entorno social, lo no verbal, que incluye gestos y posturas, era utilizado 
para reforzar diferencias de percepción que, asociadas a la disciplina, representan un componente de lo que Bourdieu (2003), llama habitus disciplinar, esquema que coadyuva a hacer evidente y manifiesta la posición y posesión del capital dentro del campo de la producción del conocimiento. Esta especie de capital simbólico actúa en la comunicación, y a través de ella en las relaciones, como fuentes de campo, "eran movimientos de cabeza y del cuerpo, que te decían no, o te decían sí" (Entrevistado 8, p. 11). Es, de acuerdo con el autor, una especie de hexis corporal, de "signos visibles que transcriben una imagen de sí mismo en el espacio social, y que autoriza o desautoriza las disposiciones, las frena o las prohíbe" (Bourdieu, 2003: 83). Con ello se pusieron en juego prácticas sociales impersonales y distantes para la descalificación y desacreditación, basadas en el no reconocimiento de la fuerza de los otros agentes, como lo describen algunos entrevistados.

Era una comunicación no verbal muy interesante, te voy a dar un ejemplo, había un académico de sociología, si había un tema donde sabía que iba a perder, que no iba a negociar nada, sacaba un libro y se ponía a leer o sacaba sus hojas y se ponía a calificar los exámenes. Físicamente estaba ahí, pero era una manera de desacreditar a las personas "no me importa, estoy aquí porque tengo que estar con ustedes" [...] o sea, la no verbal era así, llegó un momento que la comunicación era muy tensa, se fue deteriorando cada vez más (Entrevistado 4, pp. 11-12).

Recuerdo mucho la posición de esta persona de educación que tiene autoridad académica y moral [...] en ocasiones que hacíamos propuestas, cruzaba los brazos y empezaba a decir no con la cabeza, y decía, "uff, ya te cerraste, ya no me vas a escuchar, ya no voy a poder convencerte" [...] ella era la persona que podía descalificarlo (Entrevistado 7, p. 6).
Para los académicos, el lenguaje distingue a los grupos y marca diferencias entre los campos disciplinarios, "el lenguaje nos sigue haciendo también diferentes" (Entrevistado 8, p. 17), estratagema que se hizo efectiva en el uso de un lenguaje técnico, de un lenguaje especializado que llevaba a la incomprensión de ideas y propuestas.

Lenguaje digamos muy técnico [...] que por la diversidad de las disciplinas terminábamos, considero que en ocasiones, ni nos entendíamos. Un lenguaje tan especializado que llevaba al otro a no comprender lo que se estaba diciendo o a malinterpretarlo, o a darle otro sentido (Entrevistado 8, p. 6).

Es una interpretación, yo sentía que ellos pensaban que si no había espacio para la sociología, ellos se quedaban sin trabajo [...] era así como personal, la disciplina enmascarada de rollo académico pero en el fondo está en juego aquí mi posición, entonces había que pelear con las uñas. Un discurso argumentado, recitando a Weber dos o tres veces, y a Marx por ahí otras cuantas (Entrevistado 4, p. 12).

Estos aspectos comunicativos que le son concomitantes al proceso de socialización, incidentalmente tienen una función más amplia, impactar en el terreno de las disputas y las controversias, de la posición y la fuerza dentro de la toma de decisiones, en concreto, a la circulación y distribución del poder; elementos directamente comprometidos con las dificultades o conflictos en el trabajo curricular. Éstos se encontraban aglutinados alrededor de dos preocupaciones: la académica por establecer y salvaguardar los derechos de diseñar un producto de calidad que, a su vez, está íntimamente vinculada con la personal, de imponer mis ideas o necesidades, y automáticamente defenderlas, en el interés de asegurar una condición laboral, o bien, preservar asignaturas que aseguren la conservación de determinados contenidos. 
Pues parece que la imagen y posición de un campo disciplinar, en parte, está determinada por la reputación de sus miembros, lo que supone que, en el espacio educativo, está en juego no sólo el valor del producto, sino del académico en sí mismo, además del saber o la disciplina. Tal como lo explican algunos de los informantes.

Imponer mis intereses específicos de disciplina $[\ldots]$ creo que con argumentos y fuerza de convencimiento, permitían que esa propuesta se convirtiera en una decisión tomada (Entrevistado 7, p. 7).

Había el no poder o no querer comprender la intención del plan de estudios [...] costó trabajo entender esto de la interdisciplinariedad, lo entendí y sigo estando de acuerdo [...] entonces no era para mí algo así como [...] vamos a perder la identidad de mi disciplina (Entrevistado 5, p. 18).

Así, las relaciones fueron reguladas por fracciones denominadas conservadora y liberal, la primera de ellas caracterizada por un pensamiento tradicional y ortodoxo resistente al cambio, que aglutinaba a los académicos de mayor trayectoria y antigüedad dentro de la institución; la segunda, proclive al cambio, de ideas modernas e innovadoras, integrada por los miembros jóvenes y de más reciente incorporación a la institución, característica acentuada en el área de comunicación y psicología; con el distintivo de una formación a nivel de posgrado en una proporción mayor. $\mathrm{Al}$ respecto, Bourdieu (2000) sugiere que en la lucha de fuerzas, los que tienen mayor antigüedad en el campo quieren conservarlo intacto y los recién llegados quieren subvertirlo o cambiarlo. Así, dominantes y dominados ejercen fuerza de resistir, que aseguran el funcionamiento y distribución del poder a través de la organización, y tratan de hacerlo de acuerdo con las estrategias que consideren más adecuadas, intensificando el conflicto y la lucha.
Hay una rivalidad por los que se dicen viejos, como la vieja guardia y los jóvenes [...] comunicación y psicología tienen una planta más joven en comparación a educación y sociología [...] se aliaban los maestros que quieren que se les reconozca su estatus por antigüedad, no por méritos académicos [...] siento que había como los que vienen a quitarnos, había profesores 'viejos' que no tenían plaza, porque aún cuando el plan no trataba de eso, detonaba muchas dinámicas (Entrevistado 5, p. 11).

Tales elementos otorgaban a las disciplinas posiciones diferenciadas para incidir significativamente en la toma de decisiones para la configuración del plan de estudios, como lo expresan algunos entrevistados.

La entonces coordinadora de la carrera [...] pues como que no le interesaba o no le gustaba, o no estaba conforme con el equipo que estaba trabajando la reestructuración (Entrevistado 6, p. 5).

La coordinadora siempre estaba como espectadora [...] sólo si se tocaba algo del grupo al que pertenecía participaba [...] hubo un abuso de poder, de por qué se había tomado una decisión, pues si ella también tenía que estar ahí (Entrevistado 4, p. 11).

Sin embargo, algunas variaciones ocurren a partir del establecimiento de alianzas, asociaciones veladas entre las disciplinas, previamente acordadas para asegurar una negociación exitosa, o sea, una decisión. En otras palabras, garantizar una posición de fuerza capaz de ser ejercida en el espacio de la representación, anclada en el reconocimiento; pero además, dichas alianzas operaron como estrategias de ejercicio de poder o autoridad, en el propósito de mantener la pureza de la disciplina, confirmar diferencias y reforzar distinciones entre actores y campos disciplinares, concretamente en la selección y definición de contenidos, materias, 
créditos, entre otros componentes del curriculum. Tal como lo señala Bourdieu (2000), dentro de un campo, los agentes que se encuentran dotados de recursos diferentes se enfrentan a través de la acción social para conservar o transformar las correlaciones de fuerza existentes.

Alianzas que emergen en función de la decisión a tomar, de intereses compartidos, cuando al parecer la propuesta que se hacía era necesaria para dos o más carreras; propiedad aunada a la soledad de algunos de los representantes. En este sentido, con frecuencia educación y comunicación conformaron una díada, como precisan algunos de los entrevistados.

Yo sentí que hicimos alianza [...] empezamos a concordar [...] nos sentíamos las sensatas, así como que éstos que no entienden y se sienten superiores $[\ldots]$ para bloquear propuestas que eran a veces irracionales (Entrevistado 6, p. 7).

Nos tocó trabajar mucho con comunicación y psicología, más en el sentido de apoyarlas [...] mirábamos cómo andaba vuelta loca [...] porque traía muy malas relaciones con su coordinador [...] para comunicación fue orientarla, para sugerir qué leer y empaparse sobre diseño (Entrevistado 1, p. 8-9).

A veces, sociología se alió a psicología en un intento de acercarse a la coordinación del comité, no obstante, las asociaciones promovidas por aquélla, compartieron la cualidad de lograr agenciarse directamente con los coordinadores de los grupos disciplinares. Otras alianzas fueron procuradas por psicología con las demás disciplinas, en específico con el área de educación, ya que son disciplinas más afines, dice un entrevistado, "por su naturaleza, una ocupa mucho de la otra" (Entrevistado 8, p. 9), pero también por las personalidades: "Se propone un contenido sobre 'psicología social' [...] dice psicología, eso nos interesa a nosotros, estamos de acuerdo, hagamos filas por ahí" (Entrevistado 8, p. 15); "Si los de psicología necesitaban que se aprobaran dos materias en el área básica, acá por abajo o fuera del comité, cabildeaba" (Entrevistado 4, p. 13).

En consecuencia, puede observarse de forma constante y concurrente dos agrupaciones en las que las disciplinas se ordenan y organizan. Se pueden agrupar juntas en un primer momento, educación, psicología y comunicación, quedando al margen sociología, como lo expresa uno de los entrevistados, "sociología era punto y aparte, no se involucraba mucho con toda la demás gente, al principio" (Entrevistado 1, p. 7). Este posiblemente fue el bloque más permanente durante el desarrollo del trabajo, sustentado al parecer en un antagonismo y subestimación hacia la sociología, en el supuesto de "es pura retórica [...] ustedes son como discurso sociológico" (Entrevistado 8, p. 20).

Las relaciones sociales configuradas en el comité de reestructuración pueden caracterizarse como estructuradas, superpuestas y en estado constante de flujo. Por una parte pueden describirse como cordiales y de mucha disposición, con la claridad de que, como lo expresa un entrevistado, "no había relación de amistad" (Entrevistado 7, p. 3). En lo general, se pueden agrupar en el modelo de relaciones formales e impersonales, en una ambivalencia de amistad y enemistad; es decir, al exterior amistosas, al interior podían llegar a la indiferencia total, manifiestas en la diferencia de opinión que generaba reacciones de hostilidad pasiva o no abierta, mediante el no querer escuchar, ignorar y descalificar, particularmente "cuando algún pequeño grupo del comité, no estaba de acuerdo con la propuesta de otro pequeño grupo" (Entrevistado 8, p. 6). En este marco, las relaciones transitan desde un primer momento de enriquecimiento y reconocimiento de las habilidades y debilidades de los representantes, y de clarificación de referencias, a un segundo momento, 
en el cual las relaciones se vuelven más intensas, de mayor hostilidad y tensión, "las relaciones se transformaron" (Entrevistado 1, p. 8), mediatizadas principalmente por dos criterios de sociabilidad: la personalidad de los actores, y los afectos o amistades previas entre algunos de los miembros que, en lo general, determinaron los encuentros y desencuentros entre las disciplinas.

A nivel personal cuando ellos no estaban presentes, la dinámica era mucho más fluida, con más armonía, y era un comentario de todos (Entrevistado 5, p. 10).

El coordinador de una de las carreras, quería decirles a todos los demás lo que tenían que hacer, entonces esto generó en el último año serios problemas de comunicación, que muchos querían votar para que el maestro ya no acudiera a estas reuniones, era realmente conflictiva esta etapa (Entrevistado 4, p. 11).

En la estructura relacional articulada en la propiedad de la toma de decisiones, particularmente destaca la importancia de los problemas encontrados; los personales, los epistemológicos, los político-administrativos y de compromiso. Por tanto, respecto de las relaciones de poder, se encuentra que el centro corresponde a la importancia de los conceptos de disposición, comunicación, toma de decisiones y solución de problemas, propiedades estratégicas cuyas dimensiones interrelacionan los significados y las acciones de los actores. En continuidad, la interpretación gráfica de los conceptos que explican la conformación y el funcionamiento de las relaciones de poder en el proceso de DC, quedan representados en la red semántica representada en la gráfica 1 .

Se trata de una estructura relacional mediada por representaciones particulares que en conjunto matizaron el proceso de definición de los conocimientos y saberes, a través del desarrollo de un producto particular, que puede comprenderse y explicarse sólo desde las condiciones mismas de su producción, las interpretativas, pero sobre todo las sociales. De acuerdo con Tadeu da Silva (1998), el curriculum es simultáneamente espacio relacional, campo de producción, y creación de significados.

En cuanto a la noción de poder que permeó el desarrollo del proceso de DC, ésta mantuvo correspondencia con una visión jerárquica y tradicional del mismo, "si alguien hace algo, es porque la autoridad lo permite" (Entrevistado 3, p. 11). Las vicisitudes observadas lo ponderan como una práctica social de autoridad, imposición, liderazgo e influencia para inducir conductas en el logro de determinados intereses, que incluye la dominación ideológica sobre otros, ya sea individual o colectiva, construida en el consenso y con la anuencia de los dominados. Visión ampliamente coincidente con la posición de poder pronunciada por Gramsci (1998), que confirma su consideración de práctica cultural.

Pero como suele ocurrir, la expresión de relaciones de poder en el DC presupone también una perspectiva distinguible de curriculum, interpretado en la búsqueda de cambios sustanciales en la forma de estructurar los contenidos y las materias de las diversas carreras, "la idea era un DC lo más cercano a la realidad, la de la institución y la formación de los estudiantes" (Entrevistado 1, p. 14), concretizado en la imposición de una visión del mundo a través de un conocimiento dominante. Visión técnica, al potenciar la correspondencia entre la idea y la acción, orientada en la promoción del saber en cuanto un conjunto de reglas y procedimientos verdaderos e incuestionables expresados en el conocimiento de las disciplinas de forma compartimentada y atomizada (Groundy, 1998). En una representación "exactista" (Entrevistado 8, p. 23), del mismo, que lo designa como el espacio en el que se objetiva la ideología, en el 


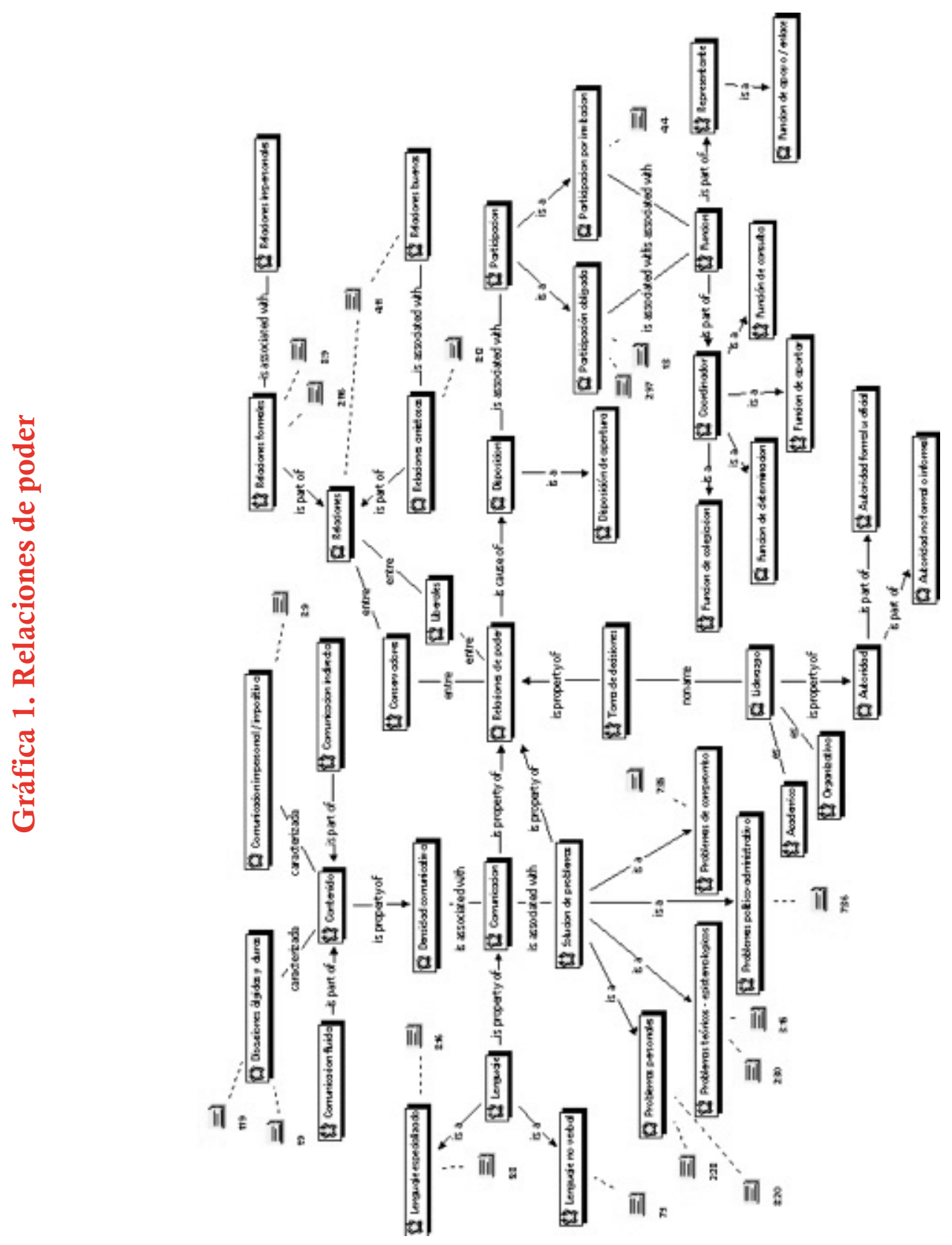


supuesto de que en la educación hay procesos de compromiso y transformación social, donde está en juego una representación del mundo, como lo refieren algunos entrevistados.

El diseño curricular lo situábamos como todas esas actividades que tenían que ver con modificar el plan de estudios vigente para transformar la parte que correspondía a la formación en objetivos y habilidades, a la de competencias (Entrevistado 2 , p. 4).

Nos permeó un manual de "metodología de diseño curricular", aportado por los miembros representantes de educación (Entrevistado 8, p. 23)

Se vio que el otro plan tenía muchas deficiencias, que en este plan se trataron de cubrir [...] se vio que hubiera avances, no retrocesos [...] como la línea de investigación, materias comunes y reconocer que todas las carreras en un momento de su vida están conectadas [...] el interés era la formación de los estudiantes, era académico, las visiones de las carreras eran diferentes, unos querían una cosa, otros otra, pero la misma carrera decidía lo que era académico, apropiado, desde su punto de vista (Entrevistado 1, pp. 14-16).

Nociones acotadas en el espíritu de la creación de un plan de estudios por competencias, cambio curricular que responda a los intereses de la formación de culturas profesionales para lograr una mejor preparación de los alumnos. Construcción social determinada por partida doble, por la posición de la disciplina en el campo, y por las categorías de percepción de los agentes asociados a tal posición.

Se está además ante un contexto cultural en el que las interacciones entre las disciplinas se fueron sedimentando como producto de un habitus disciplinar conformado en parte por la adscripción disciplinar, pero también por un campo en el cual se está inserto, al incorporar al oficio de la disciplina un sentido práctico de cómo tratar los problemas, condicionado a un sistema de esquemas de percepción y de apreciación que caracteriza al conjunto de condiciones sociales constitutivas de un estilo de actuación (Bourdieu, 2000). Estas disposiciones generadoras varían según las disciplinas para esbozar la identidad disciplinar, derivación directa de la incorporación e introyección de normas, reglas y prácticas válidas, junto a las cuales el reconocimiento y la reputación como procesos de validación de ciertas propiedades funcionan como una forma de poder, al implicar una ubicación específica en el mundo, modificable y alterable por las relaciones sociales (Berger y Luckmann, 2005). Identidad que, en el campo del saber, cumple simbólicamente una doble labor al mismo tiempo: proteger el derecho de admisión o pertenencia y ser antídoto ante la posible invasión.

En un marco en el que los grupos disciplinarios de educación, psicología, comunicación y sociología, le apostaban a sus propiedades o atributos, amalgamados a sus intereses u objetivos, estrategias y disposiciones, se buscó el logro del reconocimiento social que legitimara la forma válida de conocer el mundo; esto es, el paradigma científico. Dado que las estrategias comprometidas por los académicos eran al mismo tiempo disciplinarias y sociales, en el DC la competencia académica buscaba influir para marcar distinciones entre las disciplinas y el conocimiento, en el objetivo de lograr la valorización de un tipo de saber teórico y práctico asociado a una manera de conocer (objetos y métodos) o, como dice Bourdieu (2003), perpetuar un sistema de creencias, o mejor dicho, de inversiones al conservar la estructura del sistema.

En educación por principio existen distinciones basadas en la antigüedad, los miembros se diferencian por la membresía en función del tiempo de pertenencia al grupo, que hace posible la distinción de dos agrupaciones, la "vieja guardia y la nueva 
guardia" (Entrevistado 2, p. 14), y la integración a uno u otro determinaba el valor de la participación, la contribución y su impacto, "yo estaba recién llegada, había una dinámica muy instalada entre la gente que ya tenía muchos años" (Entrevistado 2, p. 14). En términos de Bourdieu (1993), esto puede reconocerse como los dominantes y los dominados.

Todo pesa, la experiencia, la antigüedad, que fueron las fundadoras, tenían el poder [...] no importa que estemos fuera pero aquí el poder es de nosotros [...] son muy sutiles pero educación te hace sentir "ojo porque aquí nosotros somos la élite" y si les caes bien tienes salvadas muchas cosas [...] Porque cuando se necesita el bloque se cierran y se acabó. Se cohesionan, ellos frente de ti son todos de educación, no pierden de vista eso (Entrevistado 6, p. 13).

Se presenta entonces una identidad disciplinaria construida en la base de la antigüedad, en la sedimentación de lazos de amistad y en la conformación de un bloque homogéneo, representado en la imagen de una colectividad fusionada, misma que se afianza en torno a un interés común, conservar el derecho de dominación al ser la disciplina origen, lo cual los unifica y cohesiona como grupo, con el objetivo de mantener la autoridad académica, social y moral, por tanto, el poder no formal, pero sobre todo, en la preocupación de recuperar el formal. Es un comportamiento social característicamente no acompañado del saber académico; es decir, de logros o productividad, sino prioritariamente asociado con condiciones temporales de incorporación al grupo y de relaciones extralaborales de amistad: "No aceptaban de inicio las aportaciones que yo llevaba [...] argumentos que parecían académicos, que yo creo eran de naturaleza personal [...] relaciones instituidas de las cuales yo no participé, yo llegué tarde al reparto de las influencias, entonces ahí, había voces muy respetadas" (Entrevistado 2, pp. 14-16).
En la disciplina de la psicología, se reconocía una escisión grupal que los dividía en dos fracciones, "conservadores y liberales" (Entrevistado 4 , p. 14), bloques homólogos a los existentes en educación, sin embargo, el contraste existe en la fuerza irreconciliable de los intereses de ambos subgrupos conservando la distinción. Bloques en permanente conflicto, a partir de la búsqueda de la conservación o el no cambio, sustentada en intereses personales que tenían que ver con materias, contenidos y espacios; y del otro lado, la apuesta por la innovación y el cambio, proclive a incorporar nuevos avances de la ciencia, otras temáticas y el tránsito a la transdisciplinariedad. Uno de los entrevistados comparte: "Insisto, en psicología lo que había, son cotos de poder, cuotas de docentes de su carrera [...] espacios para acomodar a sus maestros" (Entrevistado 7, p. 14).

La identidad es la de un grupo dividido y fragmentado, posicionada en la idea de un campo especializado, defendida en su mayoría por los académicos formados en otras universidades, consustancialmente de mayor edad, y la vanguardista, orientada a la idea de la interdisciplinariedad, apoyada por académicos en mayor proporción egresados de la propia universidad, que además compartían, en un número más amplio, la formación a nivel de posgrado y, como egresados recientes, menor edad cronológica y académica. La resistencia del grupo disciplinar constituía el rasgo distintivo, compensado en el argumento de la supuesta productividad académica de los miembros, al igual que la cientificidad propia de la psicología.

Eran los más renuentes a aceptar todo, y era discutir y discutir, y sacar otras cosas (Entrevistado 1, p. 6).

Por parte de psicología sí hubo mucha inconformidad en los profesores para que se diera ese plan, yo creo que si se les hubiera tomado más en 
cuenta, hubieran dicho, "está bien", o sea, proponemos esto [...] eso suscitó las reacciones de inconformidad, porque la gente se sintió excluida $[. .$.$] la representante era una representante de$ nadie porque llevaba sus propias propuestas y no llevaba las del consejo (Entrevistado 3, pp. 7-8).

Rasgos similares de polaridad se revelaron como comunes en comunicación. Se confirmaba la presencia de la denominada "vieja guardia" y "los jóvenes", que igualmente mostraban resistencia al cambio, conformando alianzas que pretendían el reconocimiento de cierto estatus por antigüedad. Conflictos de división que fueron atendidos y resueltos mediante el diálogo directo y la conciliación de intereses y preocupaciones, "los conflictos se resolvían ahí" (Entrevistado 5, p. 17).

Los compañeros se sentían muy lastimados por la coordinación anterior [...] y hubo personas que hasta el día de hoy tienen una voz más fuerte por su trabajo, su edad, su experiencia, muy respetable, entonces, estas personas manifestaban sus puntos de vista y se seguían (Entrevistado 5, p. 16).

Había otro tipo de conflictos que venían por cuestiones más personales, a mí me tocó acercarme a platicar con muchos compañeros [...] hasta la fecha seguimos trabajando y eso ha facilitado, que estemos integrados (Entrevistado 5, pp. 14-18).

Para sociología, la diferencia se da esencialmente en el hecho de que la identidad de la disciplina era protagonizada por dos actores; si bien el representante hacia señalamientos, sugerencias o propuestas, la decisión final era responsabilidad de la coordinación de la carrera; consensuadas en el interés de mostrar la valía de la disciplina, por lo que el ejercicio del poder al interior del área se presentaba en el orden de la dominación racional, a fin de regular y organizar la acción de los sociólogos, mientras que al exterior de la disciplina, es decir, en el comité de reestructuración, se intensificaba el tono de la imposición. "Finalmente la sociología tiene un valor, y ese valor le ayuda a las demás disciplinas, la sociología tiene un valor y yo como sociólogo tengo un valor, y por lo tanto, un conocimiento y que vale la pena estudiar sociología. Obviamente me aprovechaba" (Entrevistado 8, p. 21).

Circunstancia explicada por Foucault (1991), al señalar que en la base de las luchas de poder se encuentran aquellas estrategias, visiones e intereses que pueden ofrecer más dependiendo del contexto, confirmándose que como acción "el poder es necesario para limitar al poder" (Flyvbjerg, 2001: 134). "Sociología era imponer su postura a como diera lugar" (Entrevistado 4, p. 13).

De forma sucinta, la identidad de la disciplina constituye un recurso de poder sumamente significativo, por los aspectos que la configuran, pero sobre todo porque articula disposiciones subjetivas y objetivas que le confieren cierta valía. En otras palabras, reproduce la conexión entre representaciones o significados adjudicados a un conjunto de prácticas e interacciones, que en el terreno de la competencia forjan el valor simbólico de la misma. Bourdieu (2003) lo confirma, diciendo que las disciplinas hacen circular representaciones y concepciones acerca de la realidad, por lo que las luchas entre las disciplinas son por la imposición de la visión legítima de ellas, pero para los agentes involucrados, tienen el sentido de alcanzar o conservar ventajas simbólicas o materiales. En este proceso curricular, uno de ellos era conquistar la dirección de la Facultad.

En continuidad, la siguiente red semántica representa, a partir del análisis cualitativo de los discursos proporcionados por los entrevistados, los posicionamientos conceptuales que articularon la construcción y el desarrollo de la categoría de identidad disciplinar (gráfica 2). 


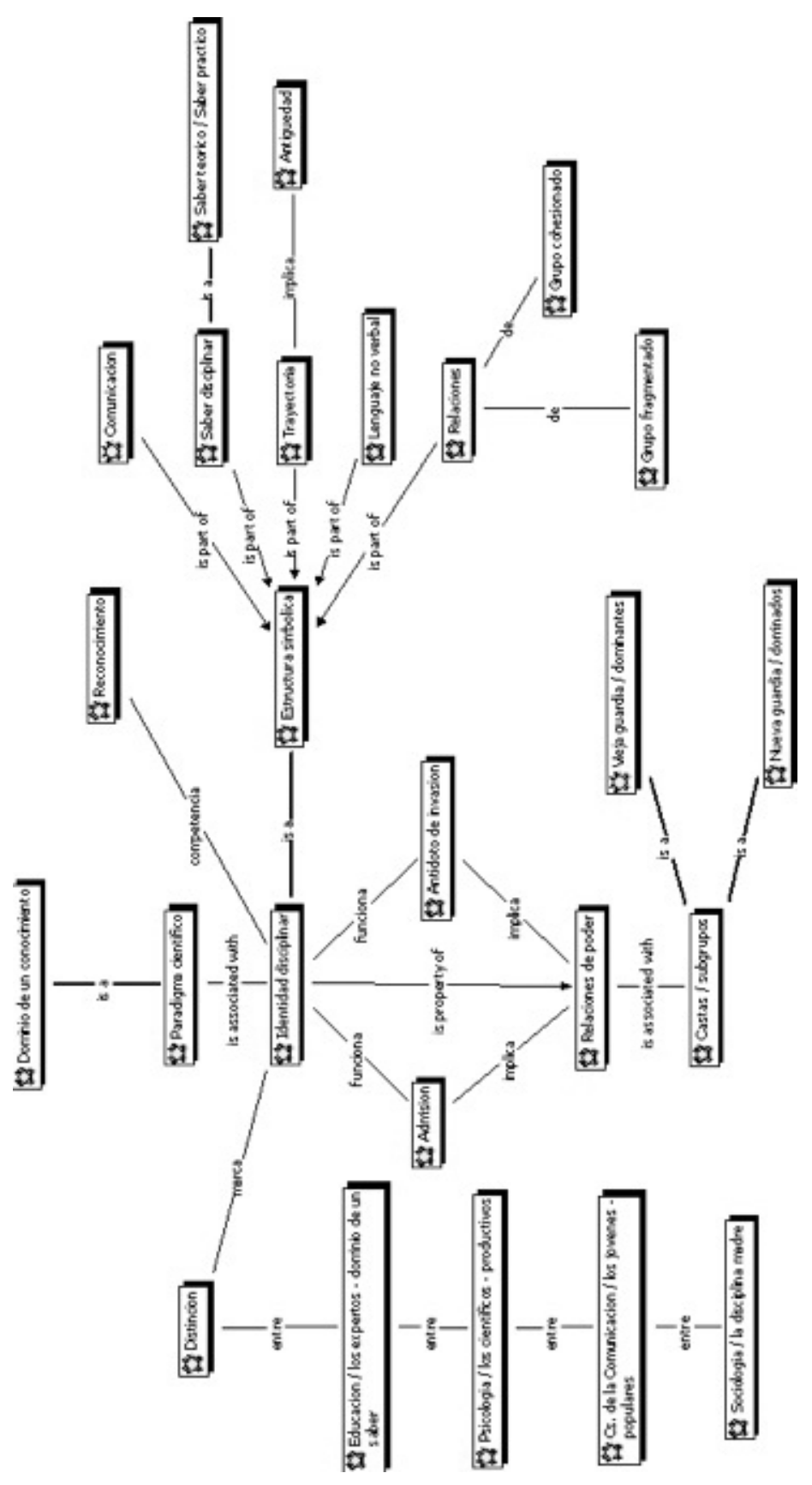




\section{Conclusiones}

Como eco, algunas reflexiones a manera de conclusión destacan que las relaciones de poder en el trabajo de diseño curricular se expresaron, en lo general, en el empuje de cada carrera para no perder su espacio y abarcar otros. Se trataba de no perder el poder en términos del dominio de un área del saber, de una disciplina sobre las demás, así como de la capacidad de imposición de asignaturas y contenidos específicos, unificadas en torno a tres ejes: el de la resistencia, la contradicción con la dirección y la protección contra el ejercicio de aquél. Había divisiones en los grupos disciplinares que trastocaron la estructura relacional, promoviendo escisiones, además de las disciplinares, afectivas y de intereses.

Y de esta forma, en principio, las relaciones configuradas entre los integrantes del comité, respondían a la lógica de organizarse en torno a la tarea, a la meta y a la confianza, por tanto formales y académicas; caracterizadas en un inicio por ser enriquecedoras y de disposición, se tornaron tensas y agresivas en algunos momentos de las sesiones plenarias. Contradictoriamente, de extrema amistad y cordialidad, conformadas por grupos o parejas afectivas que marcaron la realización del trabajo. Así, las relaciones que constituyeron el tejido social en el proceso académico del DC, fueron sustancialmente relaciones de fuerza o de poder, coextensivas al contexto singular que las originaba (Foucault, 2005).

Condiciones estructurales que definieron relaciones de poder comprometidas en la búsqueda de la imposición de un saber, de la legitimación colectiva de un conocimiento que consintiera una visión del mundo (un ser y hacer), mediante la demostración de una cartera de certificados individuales que iban desde la propia formación disciplinar, pasando por las amistades y asociaciones, incluidas las trayectorias y la experiencia, culminando con la preparación académica, que en lo colectivo, agenciaron determinada reputación y reconocimiento disciplinar, es decir, tejido relacional fundado en el poder del saber (valor de la disciplina). En este sentido, la dotación particular de recursos dispuestos por cada disciplina le confirió un vector de fuerza diferente para competir en el juego de la lucha por la representación y el reconocimiento de autoridad.

En este orden de ideas, los grupos disciplinares combinan en su esencia tanto aspectos sociológicos como académicos, reconocibles en la estrecha relación estructura-negociación, pues los grupos disciplinares menos homogéneos y cohesivos (grupos fragmentados), viven procesos de negociación doblemente saturados de conflictos y luchas de poder, tanto al interior como al exterior, por lo que el logro de consensos ocurre en un ambiente saturado por una densa competencia, no sólo por el espacio, sino también por los recursos materiales o simbólicos "materias y privilegios". Por el contrario, los grupos de mayor homogeneidad (grupos cohesionados) se presentan como menos competitivos, al mostrar cierto grado de cohesión y convergencia grupal, aparentemente de consecuencias políticas, y al asignar ventajas en la exposición y defensa de los intereses colectivos, evidenciada por un claro sentido de unidad al promoverlos, lo cual inspira respeto e imitación de las otras colectividades.

Lo último es posible porque existen las condiciones estructurales propias de un campo, que incluye la amalgama de significados y de interacciones sociales. El campo, como sugiere Bourdieu, "es una red o configuración de relaciones objetivas entre disposiciones y posiciones ocupadas por los agentes, siempre en conflicto y lucha" (1983: 118); en todo caso, se trata de espacios sociales dinámicos y estructurados por puestos jerarquizados que compiten por un capital, cuya posesión ha de determinar el acceso a beneficios específicos. Así, los que tienen más antigüedad en el campo quieren conservarlo y los recién llegados quieren subvertirlo, por lo que el DC aparece como una instancia 
reproductora de relaciones sociales de dominación o poder que, como espacio, es utilizado por los sujetos a través de sus prácticas interactivas.

Fundamentalmente, el proceso curricular recrea el vínculo poder-saber, pues éste dialécticamente es estrategia producto de determinados saberes y, como tal, origen de los mismos. Ello sugiere que el saber es estrategia en el ejercicio del poder, pero a la par, el poder es producto y produce tales saberes. Lo que significa que el saber da

\section{Referencias}

Acanda G., J. L. (2003), "Amor y poder o la relación imposible. Homenaje a Michel Foucault", en Temas, La Habana, núm. 35, pp. 108-119.

Acosta, A. (2002), "Gobierno y gobernabilidad universitaria. Ejes para una discusión", en Tiempo Universitario, Venezuela, Universidad de Carabobo, núm. 359, pp. 1-4.

Acosta, A. (2006), Poder, gobernabilidad y cambio institucional en las universidades públicas en México, 1990-2000, Jalisco, Universidad de Guadalajara.

Álvarez-Gayou, J. (2005), Cómo hacer investigación cualitativa Fundamentos y metodología, Barcelona, Paidós.

Apple, M. (1990), Política, economía y poder en la educación, México, Universidad Autónoma de Hidalgo.

Ball, S. J. (1989), La micropolitica de la escuela. Hacia una teoría de la organización escolar, Barcelona, Paidós.

Becher, T. (2001), Tribus y territorios académicos. La indagación intelectual y las culturas de las disciplinas, Barcelona, Gedisa.

Berger y Luckmann (2005), La construcción social de la realidad, Buenos Aires, Amorrortu.

Bourdieu, P. (1983), Campo del poder y campo intelectual, Buenos Aires, Folios.

Bourdieu, P. (1990), Sociología y cultura, México, Grijalbo.

Bourdieu, P. (1993), Cosas dichas, Barcelona, Gedisa. poder, pero también define el saber, así, es explicable que en el campo del conocimiento y en el espacio del diseño curricular, el que lo sustenta define cosas, y tiene la posibilidad de dictar o imponer en el discurso la verdad. Foucault (1991), en su visión relacional, subraya que en el contexto de las estrategias el saber se sitúa como alternativa de ejercicio de poder, y que este saber tiene su origen y desarrollo en el mismo sistema de relaciones de poder.

Bourdieu, P. (2000), Poder, derecho y clases sociales, Bilbao, Desclée de Brouwer.

Bourdieu, P. (2003), El oficio del científico Ciencia de la ciencia y la reflexibilidad, Barcelona, Anagrama.

Bourdieu, P. y J. C. Passeron (2003), Los herederos, los estudiantes y la cultura, Argentina, Siglo XXI.

Blase, J. (1991), "La micropolítica de la enseñanza", en B. Biddle, T. Good e I. Goodson (2000), La enseñanza y los profesores II. La enseñanza y sus contextos, Barcelona, Paidós, pp. 253-289.

Creswell, J. W. (1998), Qualitative inquiry and research design-choosing among five traditions, Londres, Sage.

Flachsland, C. (2003), Pierre Bourdieu y el capital simbólico, Madrid, Campo de Ideas.

Flyvbjerg, B. (2001), "Habermas y Foucault: pensadores de la sociedad civil?", en Estudios Sociológicos, México, Colegio de México, núm. 19, pp. 295-324.

Foucault, M. (1991), Microfisica del poder, Madrid, Las Ediciones de la Piqueta.

Foucault, M. (1993), Las redes del poder, Buenos Aires, Almagesto.

Foucault, M. (2005), Vigilar y Castigar. Nacimiento de la prisión, Buenos Aires, Siglo XXI Editores.

Giroux, H. A. (2003), Pedagogía y politica de la esperanza. Teoría, cultura y enseñanza, Buenos Aires, Amorrortu Editores.

Goodson, I. (2000), La enseñanza y los profesores II. La enseñanza y sus contextos, Barcelona, Paidós. 
Gramsci, A. (1998), Cuadernos de la cárcel. Notas sobre Maquiavelo, sobre politica y sobre el Estado moderno tomo I, México, Juan Pablos.

Groundy, S. (1998), Producto o praxis del curriculum, Madrid, Morata.

Guareschi, M. (2005), "Del modelo institucionaljurídico a la analítica del poder: Michael Foucault", en G. Duso, El poder para una historia de la filosofía política moderna, México, Siglo XXI, pp. 380-386.

Hernández, P. (1998), Diseñar y enseñar. Teoría $y$ técnicas de la programación y del proyecto docente, España, Narcea.

Kemmis, S. (2003), El curriculum: más allá de la teoría de la reproducción, Madrid, Ediciones Morata.

Kornblit, A. L. (2004), Metodologías cualitativas en ciencias sociales, Buenos Aires, Biblos.
Quinn P., M. (1980), Qualitative evaluation and research methods, Cincinnati, Sage Publications.

Strauss, A. y J. Corbin (2002), Bases de la investigación cualitativa. Técnicas y procedimientos para desarrollar la teoría fundamentada, Medellín, Universidad de Antioquia.

Tadeu da Silva, T. (1998), "Cultura y currículum como prácticas de significación”, en Revista de Estudios del Curriculum, Barcelona, Ediciones PomaresCorredor, núm. 1, pp. 59-76.

Taylor, S. (1987), Introducción a los métodos cualitativos de investigación, la búsqueda de significados, Barcelona, Paidós.

Weber, M. (2007), Sociología del poder. Los tipos de dominación, Madrid, Alianza Editorial.

\section{Cómo citar este artículo:}

Santillán-Briceño, Victoria-Elena, Ángel-Manuel Ortiz-Marín y José-Luis Arcos-Vega (2010), "El poder y las prácticas de poder de la universidad pública: Universidad Autónoma de Baja California.", en Revista Iberoamericana de Educación Superior (RIES), México, ISSUE-UNAM/Universia, vol. I, núm. 2, pp. 33-58, http://ries.universia.net/ index.php/ries/article/view/54/poder [Consulta: fecha de última consulta]. 